\section{The never ending success story of tranexamic acid in acquired bleeding}

\author{
Massimo Franchini ${ }^{1}$ and Pier Mannuccio Mannucci ${ }^{2}$ \\ ${ }^{1}$ Department of Transfusion Medicine and Hematology, Carlo Poma Hospital, Mantova and \\ ${ }^{2}$ Fondazione IRCCS Ca' Granda Ospedale Maggiore Policlinico, Angelo Bianchi Bonomi \\ Hemophilia and Thrombosis Center, Milan, Italy
}

\section{ABSTRACT}

$\mathrm{T}$ ranexamic acid (TXA) is an anti-fibrinolytic agent that acts by inhibiting plasminogen activation and fibrinolysis. Although its first clinical use dates back more than 50 years, this hemostatic agent is still the object of intense clinical and developmental research. In particular, renewed interest in TXA has arisen following evidence that it has a beneficial effect in reducing blood loss in a variety of medical and surgical conditions at increased risk of bleeding. Given this characteristic, TXA is currently considered a mainstay of Patient Blood Management programs aimed at reducing patients' exposure to allogeneic blood transfusion. Importantly, recent large randomized controlled trials have consistently documented that the use of TXA confers a survival advantage in a number of globally critical clinical conditions associated with acute bleeding, including traumatic injury and post-partum hemorrhage, without increasing the thromboembolic risk.

\section{Introduction}

Tranexamic acid (TXA) is a synthetic anti-fibrinolytic amino acid derivative of lysine that acts by competitively blocking the lysine binding sites on plasminogen, thereby inhibiting its interaction with formed plasmin and fibrin. ${ }^{1,2}$ Inhibition of plasminogen activation results in the stabilization of the preformed fibrin meshwork produced by the coagulation cascade. Thanks to its ability to inhibit fibrinolysis and clot degradation TXA, which is approved for intravenous, oral and topical applications, has been successfully employed to prevent or decrease blood loss in a variety of clinical conditions characterized by excessive bleeding. ${ }^{3,4}$ There is indeed consistent evidence that the early administration of TXA confers a survival benefit in the setting of severe trauma $a^{5,6}$ and post-partum hemorrhage without an increase in thromboembolic events. ${ }^{7}$ In addition, this agent has been successfully used to decrease blood loss in numerous surgical specialties, especially in the frame of cardiac and major orthopedic surgery. ${ }^{8.11}$ For this reason, TXA is currently considered a fundamental pillar of the Patient Blood Management (PBM) programs of transfusion medicine, aimed at minimizing blood loss and thus exposure of patients undergoing elective surgery to allogeneic blood. ${ }^{12-14}$ In this narrative review we summarize the most recent clinical evidence on the use of TXA for prevention or treatment of bleeding.

\section{Search methods}

We analyzed the medical literature for published articles on the use of TXA for bleeding. The MEDLINE electronic database was searched for publications during the last 20 years using English language as a restriction. The Medical Subject Heading and key words used were: "tranexamic acid", "bleeding", "hemorrhage", "treatment", "prevention", "patient blood management", "anti-fibrinolytic", "surgery", "cardiac surgery", "orthopedic surgery", "post-partum hemorrhage", "obstetric", "trauma", "injury" and "traumatic brain injury". We also screened the reference lists of the most relevant review articles for additional studies not captured in our initial literature search. Finally, abstracts from relevant conferences or scientific meetings were hand-searched for additional studies.
Haematologica 2020

Volume 105(5):1201-1205

\section{Correspondence:}

PIER MANNUCCIO MANNUCCI

piermannuccio.mannucci@policlinico.mi.it

Received: March 3, 2020.

Accepted: March 16, 2020.

Pre-published: March 26, 2020.

doi:10.3324/haematol.2020.250720

Check the online version for the most updated information on this article, online supplements, and information on authorship \& disclosures: www.haematologica.org/content/105/5/1201

(C)2020 Ferrata Storti Foundation

Material published in Haematologica is covered by copyright. All rights are reserved to the Ferrata Storti Foundation. Use of published material is allowed under the following terms and conditions:

https://creativecommons.org/licenses/by-nc/4.0/legalcode. Copies of published material are allowed for personal or internal use. Sharing published material for non-commercial purposes is subject to the following conditions:

https://creativecommons. org//icenses/by-nc/4.0/legalcode, sect. 3. Reproducing and sharing published material for commercial purposes is not allowed without permission in writing from the publisher. 


\section{Tranexamic acid for the prevention of bleeding}

There is a growing body of evidence documenting the efficacy of TXA in preventing bleeding in a variety of major surgical procedures, especially cardiac surgery, in the frame of PBM programs., ${ }^{8,13}$ In a systematic review and meta-analysis, TXA was shown to reduce blood losses in surgical patients by nearly one-third compared to placebo. ${ }^{15}$ These results were consistent with those of a Cochrane systematic review, including 129 trials with 10,488 participants, which showed that TXA reduced the probability of receiving a blood transfusion by one third [relative risk (RR) $0.62,95 \%$ confidence interval $(95 \% \mathrm{CI}$ ): $0.58-0.65 ; P<0.001) .{ }^{9}$ More recently, TXA has been widely used to minimize bleeding and exposure to allogeneic blood transfusion in major orthopedic surgery. Several large randomized controlled trials (RCT) and meta-analyses have consistently confirmed that the intravenous administration of this medication effectively and safely reduces perioperative blood loss and transfusion requirements at the time of major orthopedic operations such as total hip and knee arthroplasty. ${ }^{10}$ Some concerns still remained among users over the hypothetical increased risk of thromboembolic complications following the systemic infusion of this anti-fibrinolytic agent, because orthopedic surgery is associated not only with a high risk of bleeding but also of thrombosis. Thus, to refute this unjustified, non-evidence-based perception which represents the main obstacle to a broader use of TXA in this clinical context, we recently conducted a systematic review and meta-analysis of the literature aimed at assessing the safety of intravenous TXA in patients undergoing major orthopedic surgery. ${ }^{16}$ After a meta-analytic pooling of 73 RCT involving 4,174 patients and 2,779 controls, there was a similar incidence of venous thromboembolism in patients and controls $(2.1 \%$ vs. $2.0 \%)$, which established the safety of this pharmacological treatment in a PBM setting. ${ }^{16}$ In addition, a recent systematic review and meta-analysis of five RCT involving 457 patients undergoing total hip arthroplasty concluded that the combined use of intravenous and topical TXA is more effective than intravenous TXA alone in terms of reduction of blood loss, hemoglobin decline and need for transfusion without increasing the rate of thromboembolic complications. ${ }^{17}$ The recently published Recommendations for the implementation of PBM programs in orthopedic surgery, edited by the Italian National Blood Center in collaboration with several scientific societies, supported the preoperative and/or postoperative use of TXA in total hip and knee replacement surgery (grade $2 \mathrm{~A}$ recommendation). ${ }^{18}$

Given the efficacy of TXA in various conditions at potential risk of severe bleeding, several groups also evaluated its use in preventing obstetric hemorrhage. ${ }^{19,20}$ Postpartum hemorrhage ( $\mathrm{PPH})$ is a leading cause of premature maternal mortality globally, accounting for at least 100,000 deaths each year worldwide. ${ }^{21}$ A Cochrane systematic review that evaluated TXA in the prevention of $\mathrm{PPH}$ was recently published. In the frame of an analysis of 12 RCT involving 3,285 women, TXA decreased postpartum blood loss, prevented PPH and lowered blood transfusion requirements. ${ }^{22}$ We have recently conducted a systematic review and meta-analysis on the use of TXA for PPH prevention in women undergoing Cesarean delivery. ${ }^{23}$ After an in-depth analysis of 18 RCT involving
4,557 women, it was found that prophylactic use of TXA significantly reduced the incidence of $\mathrm{PPH}$, total blood loss and transfusion requirements without increasing the risk of thromboembolic complications, thus supporting its beneficial effect in this critical clinical setting. Accordingly, the most recent multidisciplinary consensus statement on prevention and treatment of $\mathrm{PPH}$ from the Network for the Advancement of Patient Blood Management, Haemostasis and Thrombosis (NATA) recommends intravenous of TXA for women at increased risk of PPH (grade $1 \mathrm{C}$ recommendation). ${ }^{19}$

On the whole, these multiple and consistent findings show that TXA is effective at preventing bleeding complications in a variety of medical and surgical conditions without increasing the risk of thrombosis.

\section{Tranexamic acid in acute bleeding conditions}

In addition to the preventive use of TXA, a number of studies have investigated the role of this anti-fibrinolytic agent in patients presenting with acute, critical bleeding. ${ }^{5,62426}$ In trauma patients, the largest body of evidence stems from the Clinical Randomisation of an Antifibrinolytic in Significant Haemorrhage (CRASH) trials. In the CRASH-2 trial, 20,211 severely injured adults with confirmed or suspected hemorrhage were randomly assigned within $8 \mathrm{~h}$ from the occurrence of trauma to receive TXA (loading bolus dose of $1 \mathrm{~g}$ and then an infusion of $1 \mathrm{~g}$ over $8 \mathrm{~h}$ ) or placebo. ${ }^{27}$ Despite no difference in bleeding rate and transfusion use, all-cause mortality was lower in the treatment group than in the placebo group ( $14.5 \%$ vs. $16 \%$, respectively; RR $0.91 ; 95 \%$ CI: $0.85-$ $0.97, P=0.0035)$. Similarly, the rate of deaths attributed to bleeding was reduced from $5.7 \%$ to $4.9 \% \quad(P=0.0077)$ (Table 1). Yet, from a sub-analysis of CRASH-2, the timing of TXA administration was crucial for patients' outcomes. ${ }^{28}$ Early infusion of TXA within $1 \mathrm{~h}$ after trauma was associated with the largest survival benefit (absolute reduction $=2.4 \%$, number needed to treat $=41$ ). TXA infused between 1 and $3 \mathrm{~h}$ also reduced the risk of death due to bleeding (absolute reduction $=1.3 \%$, number needed to treat $=77$ ), but a later administration $(>3 \mathrm{~h}$ after trauma) was associated with an increased risk of death from bleeding compared with the risk among patients receiving placebo (RR 1.44, 95\% CI: 1.12-1.84; $P=0.004){ }^{28}$ There was no evidence that TXA increased the risk of vascular occlusive events and, in a pre-specified analysis of the data collected when TXA was given within $3 \mathrm{~h}$ of injury, there was even a reduction in the odds of fatal and non-fatal vascular occlusive events (odds ratio $=0.69,95 \%$ CI: $0.53-0.89 ; P=0.005) .{ }^{29}$ Following the publication of this study, the World Health Organization (WHO) included TXA in their list of essential medicines (available at: http://Www.who.int/selection_medicines/committees/expert/18/applications/tranexamic/en). Since this seminal study, a number of randomized clinical trials, systematic reviews and meta-analyses on the efficacy of anti-fibrinolytic agents have been published. The Cochrane systematic review regarding anti-fibrinolytic drugs for acute traumatic injury found that, after the analysis of four trials involving 20,548 patients, TXA reduced the risk of death by $10 \%$ (RR 0.90, 95\% CI: $0.85-0.96 ; P=0.002$ ) without increasing the risk of adverse events. ${ }^{30}$

TXA has also been extensively studied in the setting of 
Table 1. Main results of randomized clinical trials assessing the use of tranexamic acid for acute bleeding.

\begin{tabular}{|c|c|c|c|}
\hline Î́ial & Study design & Patients enrolled & Main results \\
\hline CRASH-2 $27-29$ & $\begin{array}{l}\text { Trauma patients with or at risk } \\
\text { of hemorrhage randomized to } \\
\text { receive TXA or placebo }\end{array}$ & $\begin{array}{l}\text { 20,211 patients (10,096 in TXA group } \\
\text { and } 10,115 \text { in placebo group) }\end{array}$ & $\begin{array}{l}\text { Reduction of any cause of death in TXA group versus placebo group (RR=0.91, } \\
95 \% \text { CI: } 0.85-0.97, P=0.0035) \text {; reduction of bleeding-related deaths in TXA } \\
\text { group versus placebo group (RR=0.85, 95\% CI: } 0.76-0.96, P=0.0077) \text {; largest } \\
\text { reduction when TXA was administered within } 1 \text { h after trauma } \\
(\mathrm{RR}=0.68,95 \% \mathrm{CI}: 0.57-0.82, P<0.0001)\end{array}$ \\
\hline CRASH-333 & $\begin{array}{l}\text { Patients with traumatic brain } \\
\text { injury }(<3 \mathrm{~h}) \text { randomized } \\
\text { to receive TXA or placebo }\end{array}$ & $\begin{array}{l}12,737 \text { patients ( } 6406 \text { in TXA group } \\
\text { and } 6331 \text { in placebo group) }\end{array}$ & $\begin{array}{l}\text { Reduction of the risk of head injury-related death in patients with } \\
\text { mild-to-moderate head injury receiving TXA (RR } 0.78,95 \% \mathrm{CI} 0.64-0.95) \text {; } \\
\text { early TXA treatment was more effective than later TXA treatment in } \\
\text { patients with mild and moderate head injury }(P=0.005)\end{array}$ \\
\hline WOMAN $^{38}$ & $\begin{array}{l}\text { Women with post-partum } \\
\text { hemorrhage randomized } \\
\text { to receive TXA or placebo }\end{array}$ & $\begin{array}{l}20,060 \text { women (10,051 in TXA group } \\
\text { and 10,009 in placebo group) }\end{array}$ & $\begin{array}{l}\text { Reduction of deaths due to bleeding in women given TXA }(\mathrm{RR}=0.81 \text {, } \\
95 \% \mathrm{CI}: 0.65-1.00 ; P=0.045) \text {, especially in women given treatment within } \\
3 \mathrm{~h} \text { of giving birth (RR=0.69, } 95 \% \mathrm{CI}: 0.52-0.91 ; P=0.008)\end{array}$ \\
\hline
\end{tabular}

TXA, tranexamic acid; RR, relative risk; $\mathrm{CI}$, confidence interval.

traumatic brain injury, a leading cause of trauma deaths often associated with alterations of hemostasis with the features of hyperfibrinolysis. ${ }^{24,31}$ Meta-analysis of two randomized trials examining the effect of TXA on outcomes following traumatic brain injury showed a significant reduction in the progression of intracranial hemorrhage. ${ }^{32}$ The results of the CRASH- 3 trial were published recently. ${ }^{33}$ This trial included 12,737 patients who had isolated acute traumatic brain injury (which occurred within $3 \mathrm{~h}$ of random assignment to receive TXA (loading dose 1 $\mathrm{g}$ over 10 minutes , then infusion of $1 \mathrm{~g}$ over $8 \mathrm{~h}$ ) or placebo. TXA failed to reduce the primary endpoint, i.e. the risk of head injury-related death. However, after the exclusion of patients too severe to be saved, namely those with a Glasgow Coma Scale score of 3 or unreactive bilateral pupils at baseline, TXA reduced the risk of head injury-related deaths compared to placebo $(12.5 \%$ vs. $14.0 \%$; RR 0.89, 95\% CI: 0.80-1.00). In particular, TXA decreased the risk of injury-related deaths in patients with mild-to-moderate head injury (RR 0.78, 95\% CI: 0.64-0.95) but not in those with severe head injury (Table 1). As in CRASH-2, early treatment was more effective than more delayed treatment in patients with mild and moderate head injury $(P=0.005)$, with a $10 \%$ decrease in treatment effectiveness for every 20 min delay. The risk of vascular occlusive events was similar in the TXA and placebo groups..$^{33}$ Notably, the CRASH-3 trial was the first RCT to show that a drug has neuroprotective properties for patients with traumatic brain injury and even reduced mortality. Finally, a very recently published meta-analysis of six RCT on the effect of TXA, compared with placebo, on traumatic brain injury showed that this medication was associated with a reduced mortality (RR 0.91, 95\% CI: $0.85-0.97 ; P=0.0004){ }^{34}$

Very recent evidence also indicates that TXA usage results in a significant reduction of obstetric bleeding. ${ }^{55-37}$ In the landmark randomized, double blind World Maternal Antifibrinolytic (WOMAN) trial, more than 20,000 women with PPH following vaginal or Cesarean delivery were assigned to receive either TXA (1 g TXA intravenously as soon as possible, followed by a further 1 $\mathrm{g}$ if bleeding continued after 30 min or restarted within 24 $\mathrm{h}$ of the initial dose) or placebo. ${ }^{38}$ The trial showed a decreased overall mortality due to bleeding in the TXA group (RR 0.81, 95\% CI: 0.65-1.00; $P=0.045$ ) (Table 1), and no differences in venous or arterial thromboembolic events were observed between women in the two arms. Similarly to the CRASH trials, in the WOMAN trial patients receiving TXA within $3 \mathrm{~h}$ from delivery had the most marked mortality reduction (89 deaths in the TXA group vs. 127 deaths in the placebo group, RR 0.69, 95\% CI: $0.52-0.91 ; P=0.008) .{ }^{38}$ Thanks to the results of this global trial, a 2017 World Health Organization recommendation for the treatment of PPH states that TXA should be recognized as a life-saving intervention and thus made readily available for the management of $\mathrm{PPH}$ in settings in which emergency obstetric care is provided, regardless of the level of healthcare system resources. ${ }^{39}$ In addition, the recent NATA consensus statement recommends the administration of TXA ( $1 \mathrm{~g}$ by intravenous route) as soon as possible within the first $3 \mathrm{~h}$ after $\mathrm{PPH}$ onset, with this dose repeated after 30 min if bleeding continues (grade $1 \mathrm{~B}$ recommendation). ${ }^{19}$

All in all, these large trials document with unequivocal evidence the beneficial effect of early administration of TXA in an array of patients with acute critical bleeding, without increasing the risk of adverse events. ${ }^{40,41}$

\section{Conclusions}

Although TXA has been known for more than 50 years, its successful use never ceases to amaze us. The incredible current interest in this old drug is demonstrated by the increasing number of PubMed citations (589 in 2019) and by the high number of trials listed at clinicaltrials.gov (432 at the time of writing). The current evidence in the literature documents the efficacy and safety of TXA in preventing bleeding in a variety of at-risk conditions and thanks to this effect TXA is nowadays an essential drug in the therapeutic armamentarium of PBM-based protocols developed by the majority of hospitals worldwide with the aim of minimizing patients' exposure to allogeneic blood. ${ }^{42}$

The most recently published data show unequivocally that TXA also plays a prominent role in the management of critical bleeding. Indeed, considering the results of the CRASH-2, CRASH-3 and WOMAN trials (remarkably, CRASH-2 and CRASH-3 trials were truly independent research, not funded by pharmaceutical companies), more than 50,000 bleeding patients have been investigated so far for the hemostatic effect of TXA. Although 
with different designs, the results of these trials are very similar and clear: TXA is effective in reducing the risk of death due to bleeding regardless of the cause. Furthermore, all these three trials identified early administration of the drug as a crucial issue for improving patients' outcome.

Additional striking evidence of the beneficial effect of TXA in acute trauma patients comes from the increasing use of this agent in the military setting. ${ }^{6}$ Indeed, the positive results of the CRASH-2 trial, conducted in civilian trauma populations, triggered a series of studies evaluating TXA in combat trauma patients. ${ }^{5}$ The largest trial was the retrospective observational Military Application of Tranexamic Acid in Trauma Emergency Resuscitation study (MATTERs), ${ }^{43}$ which evaluated TXA in subjects with combat-related injury and found that the addition of this anti-fibrinolytic agent to blood component-based resuscitation resulted in a survival improvement, particularly in patients requiring massive transfusion. Thus, on the basis of the findings from the previously mentioned trials, early administration (within $3 \mathrm{~h}$ of injury) of TXA is now globally incorporated as an essential therapeutic strategy in the majority of resuscitation protocols, not only in civilian but also in military trauma centers.

Finally, we would like to outline the safety aspects that emerge from an overall analysis of the various RCT. The risk of thromboembolic events - including pulmonary embolism, deep-vein thrombosis, myocardial infarction and stroke - did not differ between the TXA and placebo groups. These data provide definitive strong evidence demonstrating the safety of TXA and render any residual concern unjustified.

\section{References}

1. Mannucci PM. Hemostatic drugs. N Engl J Med. 1998;339(4):245-253.

2. Franchini M, Mannucci PM. Adjunct agents for bleeding. Curr Opin Hematol. 2014;21(6):503-508.

3. Schulman S. Pharmacologic tools to reduce bleeding in surgery. Hematology Am Soc Hematol Educ Program. 2012;2012:517521.

4. Cai J, Ribkoff J, Olson S, et al. The many roles of tranexamic acid: an overview of the clinical indications for TXA in medical and surgical patients. Eur J Haematol. 2020; 104(2):79-87.

5. Ramirez RJ, Spinella PC, Bochicchio GV. Tranexamic acid update in trauma. Crit Care Clin. 2017;33(1):85-99.

6. Lier H, Maegele M, Shander A. Tranexamic acid for acute hemorrhage: a narrative review of landmark studies and a critical reappraisal of its use over the last decade. Anesth Analg. 2019;129(6):1574-1584

7. Hibbs SP, Roberts I, Shakur-Still H, Hunt BJ. Post-partum haemorrhage and tranexamic acid: a global issue. Br J Haematol. 2018;180(6):799-807

8. Gerstein NS, Brierley JK, Windsor J, et al. Antifibrinolytic agents in cardiac and noncardiac surgery: a comprehensive overview and update. J Cardiothorac Vasc Anesth. 2017;31(6):2183-2205

9. Henry DA, Carless PA, Moxey AJ, et al. Anti-fibrinolytic use for minimising perioperative allogeneic blood transfusion. Cochrane Database Syst Rev. 2011;(3): CD001886.

10. Jiang X, Ma XL, Ma JX. Efficiency and safety of intravenous tranexamic acid in simultaneous bilateral total knee arthroplasty: a systematic review and meta-analysis. Orthop Surg. 2016;8(3):285-293.

11. Lin ZX, Woolf SK. Safety, efficacy, and cost-effectiveness of tranexamic acid in orthopedic surgery. Orthopedics. 2016:39(2):119-130.

12. Franchini $M$, Muñoz $M$. Towards the implementation of patient blood management across Europe. Blood Transfus. 2017;15(4):292-293.

13. Franchini M, Liumbruno GM. The key role of tranexamic acid in Patient Blood Management programmes. Blood Transfus. 2018;16(6):471-472.

14. Franchini M, Marano G, Veropalumbo E, et al. Patient Blood Management: a revolutionary approach to transfusion medicine. Blood Transfus. 2019;17(3):191-195.

15. Ker K, Prieto-Merino D, Roberts I. Systematic review, meta-analysis and meta-regression of the effect of tranexamic acid on surgical blood loss. Br J Surg. 2013;100(10):1271-1279

16. Franchini $M$, Mengoli C, Marietta $M$, et al. Safety of intravenous tranexamic acid in patients undergoing major orthopaedic surgery: a meta-analysis of randomised controlled trials. Blood Transfus. 2018;16(1):3643.

17. Sun Y, Jiang C, Li O. A systematic review and meta-analysis comparing combined intravenous and topical tranexamic acid with intravenous administration alone in THA. PLoS One. 2017;12(10):e0186174.

18. Vaglio S, Prisco D, Biancofiore G, et al. Recommendations for the implementation of a Patient Blood Management programme. Application to elective major orthopaedic surgery in adults. Blood Transfus. 2016;14(1):23-65.

19. Muñoz M, Stensballe J, Ducloy-Bouthors AS, et al. Patient blood management in obstetrics: prevention and treatment of postpartum haemorrhage - NATA consensus statement. Blood Transfus. 2019;17 (2):112-136.

20. Franchini M, Liumbruno GM. Implementation of a patient blood management programme in obstetrics: let's do it! Blood Transfus. 2019;17(2):87-88.

21. Kassebaum NJ, Bertozzi-Villa A, Coggeshall MS, et al. Global, regional, and national levels and causes of maternal mortality during 1990-2013: a systematic analysis for the Global Burden of Disease Study 2013. Lancet. 2014;384(9947):9801004

22. Novikova N, Hofmeyr GJ, Cluver C. Tranexamic acid for preventing postpartum haemorrhage. Cochrane Database Syst Rev. 2015;6(6):CD007872.

23. Franchini M, Mengoli C, Cruciani M, et al. Safety and efficacy of tranexamic acid for prevention of obstetric haemorrhage: an updated systematic review and metaanalysis. Blood Transfus. 2018;16(4):329337

24. Gall LS, Davenport RA. Fibrinolysis and antifibrinolytic treatment in the trauma patient. Curr Opin Anesthesiol. 2018;31: 227-233.

25. Godier A, Roquet F, Hamada SR. Tranexamic acid: one more step towards its widespread use. Anaesth Crit Care Pain Med. 2020;39(1):15-17

26. Roberts I. Tranexamic acid in trauma: how should we use it?. J Thromb Haemost. 2015;13(Suppl. 1):S195-S199.

27. Shakur H, Roberts I, Bautista R, et al Effects of tranexamic acid on death, vascular occlusive events, and blood transfusion in trauma patients with significant haemorrhage (CRASH-2): a randomised, placebocontrolled trial. Lancet. 2010;376(9734):2332 .

28. Roberts I, Shakur H, Afolabi A, et al. CRASH-2 collaborators. The importance of early treatment with tranexamic acid in bleeding trauma patients: an exploratory analysis of the CRASH-2 randomised controlled trial. Lancet. 2011;377(9771):10961101

29. Roberts I, Perel P, Prieto-Merino D, et al. CRASH-2 Collaborators. Effect of tranexamic acid on mortality in patients with traumatic bleeding: prespecified analysis of data from randomised controlled trial. BMJ. 2012;345:e5839.

30. Ker K, Roberts I, Shakur H, Coats TJ. Antifibrinolytic drugs for acute traumatic injury. Cochrane Database Syst Rev. 2015;5:CD004896

31. Maegele M, Schochl H, Menovsky T, et al. Coagulopathy and haemorrhagic progression in traumatic brain injury: advances in mechanisms, diagnosis, and management. Lancet Neurol. 2017;16(8):630-647.

32. Zehtabchi S, Abdel Baki SG, Falzon L, Nishijima DK. Tranexamic acid for traumatic brain injury: a systematic review and meta-analysis. Am J Emerg Med. 2014;32(12):1503-1509.

33. CRASH-3 trial, collaborators. Effects of tranexamic acid on death, disability, vascular occlusive events and other morbidities in patients with acute traumatic brain injury (CRASH-3): a randomised, placebo- 
controlled, trial. Lancet. 2019;394(102210): 1713-1723

34. Chen H, Chen M. The efficacy of tranexamic acid for brain injury: a meta-analysis of randomized controlled trials. Am J Emerg Med. 2020 Oct 14. [Epub ahead of print]

35. Ducloy-Bouthors AS, Jude B, et al. EXADELI Study Group. High-dose tranexamic acid reduces blood loss in postpartum haemorrhage. Crit Care. 2011;15(2):R117.

36. Gayet-Ageron A, Prieto-Merino D, Ker K, Shakur H, Ageron FX, Roberts I. Antifibrinolytic Trials Collaboration. Effect of treatment delay on the effectiveness and safety of antifibrinolytics in acute severe haemorrhage: a meta-analysis of individual patient-level data from 40138 bleeding patients. Lancet. 2018;391(10116):125-132

37. Alam A, Choi S. Prophylactic use of tranexamic acid for postpartum bleeding outcomes: a systematic review and metaanalysis of randomized controlled trials. Transfus Med Rev. 2015;29(4):231-241

38. WOMAN Trial Collaborators. Effect of early tranexamic acid administration on mortality, hysterectomy, and other morbidities in women with post-partum haemorrhage (WOMAN): an international, randomised, double-blind, placebo-controlled trial. Lancet. 2017;389(10084):2105-2116

39. World Health Organization. WHO Recommendation on Tranexamic Acid for the Treatment of Postpartum Haemorrhage. Geneva: World Health Organization; 2017.
40. Godier A, Roberts I, Hunt BJ. Tranexamic acid: less bleeding and less thrombosis? Crit Care. 2012;16(3):135

41. Spahn DR, Bouillon B, Cerny V, et al. The European guideline on management of major bleeding and coagulopathy following trauma: fifth edition. Crit Care. 2019;23 (1):98.

42. Desai N, Schofield N, Richards T. Perioperative Patient Blood Management to improve outcomes. Anesth Analg. 2018;127(5):1211-1220

43. Morrison JJ, Dubose JJ, Rasmussen TE, Midwinter MJ. Military application of tranexamic acid in trauma emergency resuscitation (MATTERs) Study. Arch Surg. 2012;147(2):113-119. 